\title{
Robot Arm Analysis based on Master Device Pneumatic Actuators
}

\author{
Mohd Aliff ${ }^{1}$, Nor Samsiah Sani ${ }^{2}$ \\ Instrumentation and Control Engineering, Malaysian Institute of Industrial Technology, Universiti Kuala Lumpur, Johor ${ }^{1}$ \\ Center for Artificial Intelligence Technology, Universiti Kebangsaan Malaysia (UKM) ${ }^{2}$
}

\begin{abstract}
Advances in technology have expanded the use of soft actuators in various fields especially in robotics, rehabilitation and medical field. Soft actuator development provides many advantages, primarily being simple structures, high power to weight ratio, good compliance, high water resistance and low production cost. However, most soft actuators suffer the problem of being oversized which could potentially hurt users as it is often made of hard materials such as steels and hard rigid plastics. Current drawbacks of soft actuator implementation in robotic arms are on its excessive weights, causing these robots to be difficult to set up by patients themselves which in turn makes it less applicable for home rehabilitation training program. Hence, there is a need to design a soft actuator which is safe and more flexible, especially for applications in areas of patients in rehabilitation area or in-house rehabilitation program. In this paper, we propose the design of robot arm using master device pneumatic actuator and analyse the implementation for the above purpose. The system comprises primarily of the master and slave arms, two accelerometers and two potentiometers providing references for attitude control, six quasi-servo valves, and SH-7125 microcontroller. Our proposed design exhibits functions of the actuator that has been generated from elastic deformation of extension and contraction of the cylinder structure when high pneumatic pressure is supplied to the chamber. The control performance of the device is investigated using simulation method, whereby the rational model of the robot arm and the quasi servo valve with the embedded controller is implemented and analysed. It is found that the analysed results of the model approved well with the desired values.
\end{abstract}

Keywords-Trajectory control; master-slave control; robot arm; pneumatic cylinder

\section{INTRODUCTION}

A major social problem in developed countries is the alarming rise of elderly population against a continuingly declining birth rate. Such population differences have become more apparent every year, raising the concerns of various professional community from aspects of engineering, healthcare and social sciences. Today, many studies have shown a wide adoption of robot technology used in manufacturing [1], agriculture [2], communication [3], and education $[4,5]$. In the line of 4IR, there is demand for one system that can control, communicate and integrate different robots regardless of their types and specifications. As term machine learning has heated up interest in robotics has not altered much. Only a portion of recent development in robotics can be credited to development any use machine leaning. Only a portion of recent development in robotics can be credited to development any use machine leaning [6]-[10]. Recent robotic development project has embedded machine learning algorithms to increase the intelligence in robots. This will increase the productivity while reducing the cost and electronic waste in a long run.

Specifically in the healthcare industry, robots are used in range of ways from supporting nursing care [11], assist the daily activities for elderly residents [12] as well as the disabled [13], to performing complex surgical procedures in hospital's surgery situation [14]. The ability to perform work accurately and continually for extensive times is of significant merit in this scope. However, one major drawback of such robotic arms is that they are often heavy and need to be mounted on walls and pillars. This causes the room to be restricted in space and movement which thoroughly affects patients' negatively. Current robot arm products are also complicated to be installed by patients themselves and are not applicable for home rehabilitation programs [15].

In medical and rehabilitation areas, several key features for actuators are expected; light weight, portability and adaptability to expand to needs, as well as usability in various environments [16, 17]. For these reasons, choosing the right actuator is important to satisfy the above criteria. A flexible and lightweight actuator has been developed in this study and applied for robotic arm to be used as rehabilitation device. In specific, the device is a novel type of flexible pneumatic actuator with two important attributes: (i) perform well even if the actuators are impaired by the extrinsic forces [18, 19] and (ii) flexibility of the robot arm based on simple structure, which is proposed and tested using the flexible pneumatic cylinders [20, 21]. This robot arm possesses three special degrees-of-freedom characteristics which are able to bend, extend and contract. With the aim to be harnessed in physiotherapy, the master and slave device is incorporated into the robot arm, to assume the situations where the physical therapist performs movement treatment to a patient. During rehabilitation, the therapist control the robot movement by holding the master arm and move it repeatedly according to conditions and needs of the patient. Simultaneously, the user's arm placed on slave arm will actually mimic the master arm movement as presented in Fig. 1. Using a flexible pneumatic cylinder, the analysis of robot arm for the human wrist rehabilitation is introduced in this paper. The system consists of a set of master and slave arms, two accelerometers and two potentiometers providing references for attitude control, six quasi-servo valves, and SH-7125 microcontoller. Next, the analytical model of the flexible pneumatic cylinder and the 
quasi servo valve with the embedded controller was designed. A comparison of the theoretical and experimental results was then performed to verify the rationality of the designed model.

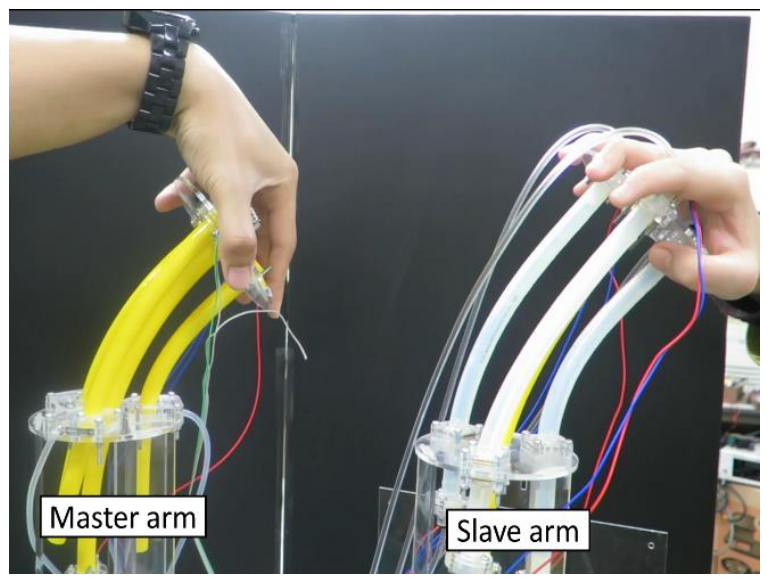

Fig. 1. Master and Slave Device of Robot Arm.

\section{MATERIAL AND METHOD}

\section{A. Structure of Robot Arm}

Construction of flexible soft tube is shown in Fig. 2. Main components of the soft tube include brass rollers, flexible tubes, slide stage as well as $9 \mathrm{~mm}$ and $3 \mathrm{~mm}$ of steel balls. Soft polyurethane tube from SMC Co Ltd (TUS 1208) has been used as a cylinder that allows air to pass through it. When air is supplied into the tube, two pairs of brass rollers from top and bottom sides are pinched on the $9 \mathrm{~mm}$ steel ball (referred as the cylinder head), allowing free movement of the steel ball. On the other hand, a $3 \mathrm{~mm}$ diameter steel ball was introduced in the middle of the slide stage and flexible tube to withstand the cylinder and brass rollers, thus enabling a natural tube movement. In addition, steel ball $(9 \mathrm{~mm})$ located amidst the slide stage was pushed and moved appropriately when pressure was given from one end of the flexible tube. In parallel, brass rollers also pushed the steel ball, moving the slide stage although it impaired the tube. Therefore, this ideal combination between center distance $(D)$ and distance $(W)$ between two couples of rollers can be a variable to find lowest handling pressure of the pneumatic cylinder. As a result, the best value for $D$ was indicated at $14.4 \mathrm{~mm}$ and $W$ at $10 \mathrm{~mm}$ after considering that this value combination caused the steel ball $(9 \mathrm{~mm})$ to not being able to escape from the slide stage and slender frictional force of the slide stage [18].

Table I highlights characteristics of flexible cylinder used in this study. Using the developed flexible pneumatic cylinders, the flexible robot arm is constructed as shown in Fig. 3 [20, 22]. The robot arm size specification is as follows: an overall diameter of $\varnothing 100 \mathrm{~mm} \times 250 \mathrm{~mm}$ with a total mass of $380 \mathrm{~g}$. It is partitioned as upper and lower round stages, fixed with a central tube, three flexible pneumatic cylinders, an accelerometer, three slide stages and a potentiometer. The preliminary distance between two round stages is about 100 $\mathrm{mm}$ after being measured using the potentiometer from Copal Electronics that was connected to the middle of the tube. The mid angle of two nearby slide stages is equal to 120 degrees on the stage following each flexible pneumatic cylinder's arrangement after its end was set to the upper stage. One of flexible pneumatic cylinder was driven by two quasi-servo valves [23, 24] which consist of four on/off valves (Koganei Co. Ltd., G010HE-1). Six control valves were needed to control the three flexible cylinders. In conditions that exerted $500 \mathrm{kPa}$ amount pressure; the maximum bending angle of the robot arm was at 45 degrees with the overall produced force of three cylinders to be that of $45 \mathrm{~N}$. The operating principle for pneumatic cylinder is shown in Fig. 2. To bend the pneumatic cylinder to the right side, pressure must be directed to both ends of the right cylinder whereas the other two cylinders are pressurized from the top [17]. On the other hand, one end of the cylinder was pressurized in order to move the robot arm upward or downward.

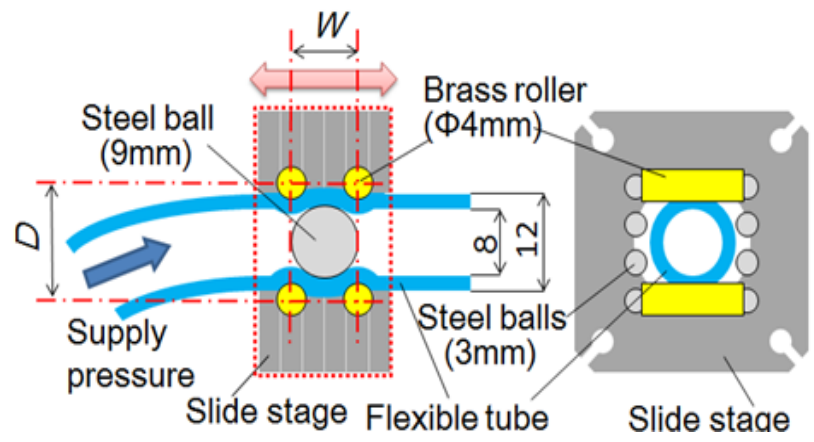

Fig. 2. Construction of the Flexible Pneumatic Cylinder.

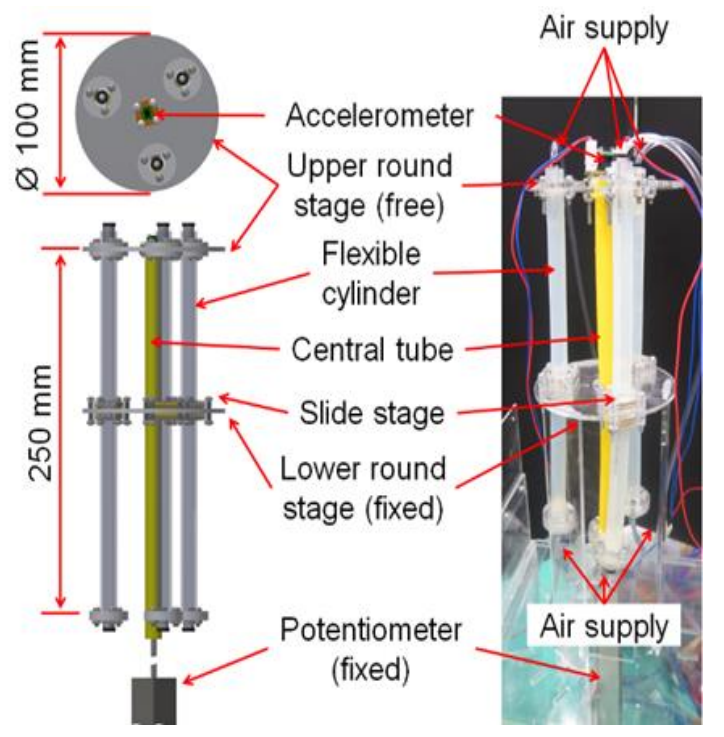

Fig. 3. Flexible Pneumatic Robot Arm.

TABLE. I. CHARACTERISTICS OF FLEXIBLE CYLINDER

\begin{tabular}{|l|l|}
\hline Weight & $<0.1 \mathrm{~kg}$ \\
\hline Pushing and pulling speed & $>1 \mathrm{~m} / \mathrm{s}$ \\
\hline Produced force & $16 \mathrm{~N}($ input:500kPa) \\
\hline Lowest handling pressure & $120 \mathrm{kPa}$ \\
\hline Maximum operational pressure & $600 \mathrm{kPa}$ \\
\hline Minimum curvature radius & about $30 \mathrm{~mm}$ \\
\hline Movement & Push-pull actions \\
\hline Effective temperature & From -20 to +60 deg.C \\
\hline
\end{tabular}




\section{B. Master Slave Control}

The geometrical relationship of robot arm is shown in Fig. 4. Once arms are curved, the form of flexible cylinder from upper stage to lower stage is presumed to always be in round arc. From the center of the robot arm, angle $\alpha$ is defined as the bending angle from $\mathrm{X}$ axis while angle $\beta$ denotes from $\mathrm{Z}$ axis to the normal vector at the centre. Following the counter clockwise starting from $\mathrm{X}$ axis, the cylinder length (displacement) of flexible pneumatic for the cylinder 1 located exactly on the $\mathrm{X}$ axis is labelled as $L 1$, followed by $L 2$ and $L 3$ for cylinder 2 and cylinder 3 respectively.

Fig. 4 shows the geometrical relationship of the robot arm, producing the following obtained Equation (1):

$R=\frac{L}{\beta}$

Furthermore, from Fig. 4, the equations for $L 1, L 2$ and $L 3$ (length of the cylinder between the upper surface of the stage and lower stage) are acquired and shown in Equations (2), (3) and (4), respectively.

$L_{1 i}=\left(R_{i}-r \cdot \cos \alpha_{i}\right) \cdot \beta_{i}$

$L_{2 i}=\left\{R_{i}-r \cdot \cos \left(\frac{2 \pi}{3}-\alpha_{i}\right)\right\} \cdot \beta_{i}$

$L_{3 i}=\left\{R_{i}-r \cdot \cos \left(\frac{4 \pi}{3}-\alpha_{i}\right)\right\} \cdot \beta_{i}$

From the above equations, $r$ is set at $33 \mathrm{~mm}$ measured as the radius of the round stage to the centre of slide stage in the cylinder. Subscripts $i=\mathrm{m}, \mathrm{s}$ indicates the master arm (desired value) and the slave arm (present value), respectively. Subscript number (1,2 and 3) indicates the location number of the cylinder. By referring to Equations (1) to (4) and based on the displacement of the master and slave cylinder, the control system can be performed. The accelerometer (Kionix KXR942050) has been used to measure the bending direction angle $\alpha$ and the bending angle $\beta$ of robot arm. This consists of a mass, a spring and a capacitance type displacement sensor. Fig. 5 shows an analytical model to calculate the value of $\alpha, \beta$, and the coordinate $X c, Y c, Z c$ of robot arm end.

$\alpha=\cos ^{-1} \frac{V_{x}}{\sqrt{V_{x}^{2}+V_{y}^{2}}}$

$\beta=\cos ^{-1}\left(\frac{V_{z}}{V_{z \max }}\right)$

$X_{c}=R \cdot(1-\cos \beta) \cos \alpha$

$Y_{c}=R \cdot(1-\cos \beta) \sin \alpha$

$Z_{c}=R \cdot \sin \beta$

$V z \max , V x, V y$, and $V z$ values signify differences of $V z$ between the values in horizontal and vertical planes and the output voltages from the accelerometer in $X, Y, Z$ axis, respectively. The length of cylinders for every bending state of the robot arm can be calculated using (Eq. 1) to (Eq. 6). From our experiments, the calculated angle shows good agreement to the measured value in which the error between the calculated angles and the measured error angles is found to be less than 1 degree $[22,24]$.

\section{Control Procedure}

Fig. 6 shows the view of the master-slave control system and its schematic diagram which consists of a slave arm and a master arm.
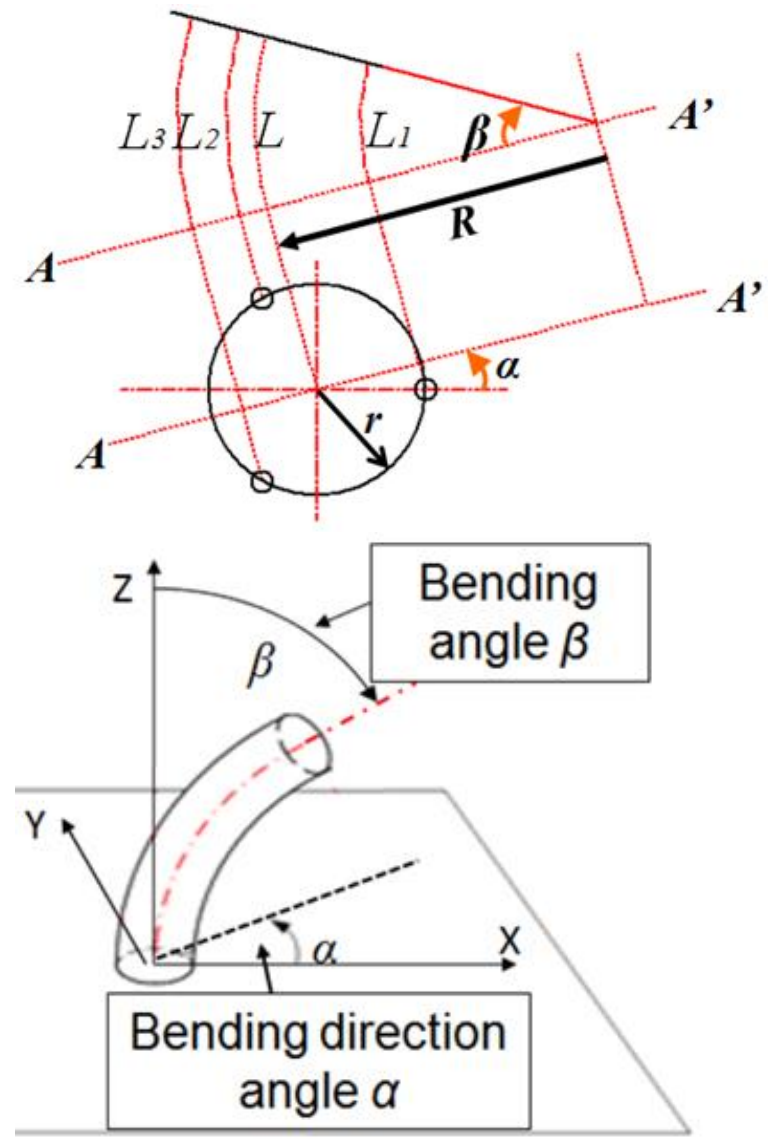

Fig. 4. The Geometrical Relationship of the Robot Arm.

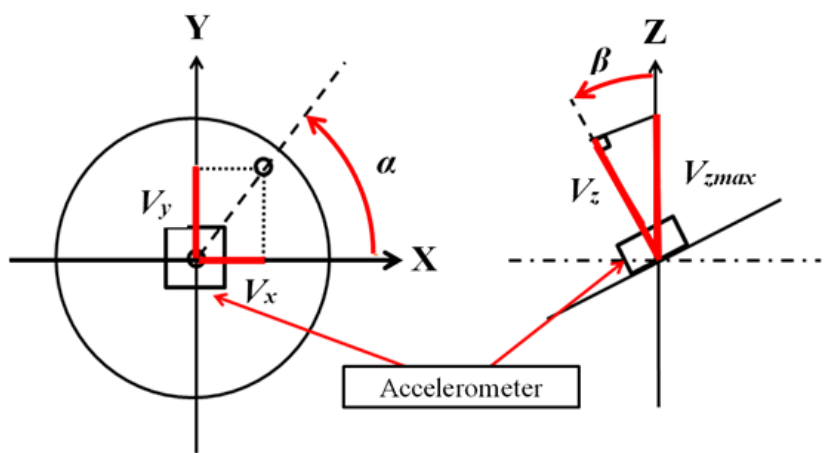

Fig. 5. The Correlation of Accelerometer Sensor with Bending Angle. 


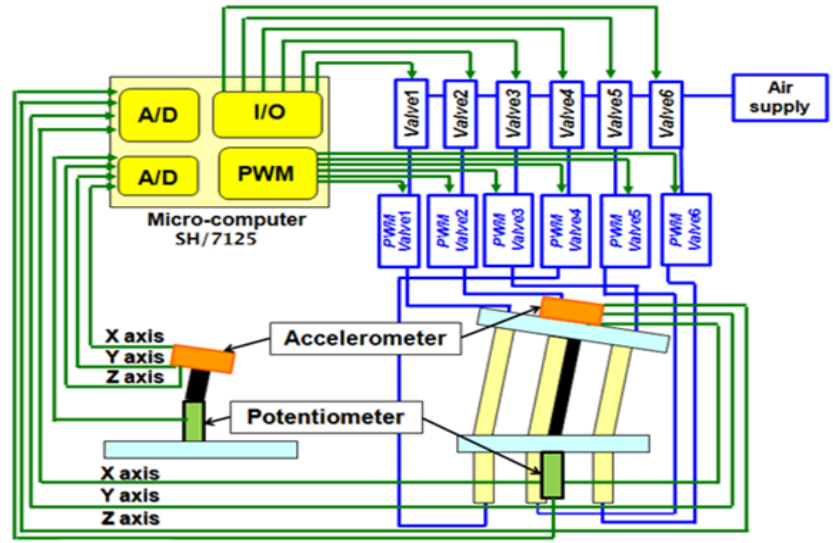

Fig. 6. Schematic Diagram for Control System.

In order to obtain the reference attitude value of the master arm, the accelerometer is set atop the upper stage. The changes of gravity for $X, Y$, and $Z$ axes, the bending angle of upper stage of master and slave arm are then detected. Output voltages of the accelerometer from master and slave arm are sent to the microcomputer as shown in Fig. 6. Sampling period for master slave control system is set as $2.3 \mathrm{~ms}$. The proposed control procedure for master-slave is described below:

1) Initially, the attitude of the master arm; the bending direction angle $\alpha \mathrm{m}$, the bending angle $\beta m$ and the distance $L_{m}$ are detected using the accelerometer and the potentiometer installed on it.

2) Distances of the master arm $L_{1 m}, L_{2 m}$ and $L_{3 m}$ are calculated by the microcomputer using the analytical model from (Eq. 1) to (Eq. 4).

3) Attitude of the slave arm; $\alpha s, \beta s$ and $L s$ are next detected by the accelerometer and the potentiometer of the slave arm. Distances $L_{1 s}, L_{2 s}$ and $L_{3 s}$ are calculated by using the analytical model.

4) Errors between $L_{j m}$ for the master arm and $L_{j s}(\mathrm{j}=1,2,3)$ for the slave arm are calculated using the microcomputer.

5) Finally, using both control system which are PWM control valve (quasi-servo valve) and PID control scheme depend on the calculated errors, the position of the cylinder can be controlled.

Another control system introduced in this paper is the trajectory control system. Such system exhibits only a slave arm. The procedure for trajectory control system using the analytical model is further described below:

1) $\mathrm{X}_{\mathrm{d}}(\mathrm{t}), \mathrm{Y}_{\mathrm{d}}(\mathrm{t}), \mathrm{Z}_{\mathrm{d}}(\mathrm{t})$ is generated.

2) The present bending direction angle $\alpha$, the bending angle $\beta$ and the length $L$ is determined using equations (5) and (6). The current arm end's coordinates $X_{c}, Y_{c}, Z_{c}$ are obtained using these calculated values. Concurrently, the present cylinder lengths L1, L2 and L3 are also calculated using Equations (1) to (4).

3) $X_{c 1}, Y_{c 1}, Z_{c 1}$ of next arm end's coordinates are deliberated from the target trajectory. The distinctions $\delta \mathrm{X}, \delta \mathrm{Y}$, $\delta \mathrm{Z}$ of current arm end's coordinates are obtained using the following equations:

$$
\begin{gathered}
\delta X=X_{c l}-X_{c} \\
\delta Y=Y_{c l}-Y_{c} \\
\delta Z=Z_{c 1}-Z_{c}
\end{gathered}
$$

4) Next, distinctions $\left(\delta_{\mathrm{Xc}}, \delta_{\mathrm{Yc}}, \delta_{\mathrm{Zc}}\right)$ of arm end's coordinates are calculated based on the divergence between the preferred position of arm end and its current position. $\alpha_{1}$, $\beta_{l}$ and $L_{l}$ are obtained using the following equations for which the preferred positions are calculated.

$\alpha_{1}=\alpha+\delta \alpha$

$\beta_{1}=\beta+\delta \beta$

$L_{l}=L+\delta L$

5) The preferred cylinder lengths $L_{11}, L_{21}$ and $L_{31}$ are determined based on calculations of $\alpha_{1}, \beta_{1}$ and $L_{1}$ from Equations (8) and Equation (1) to (4).

6) Finally, using PID control system and recapping the procedures from 2) to 5), variation of each cylinder length from the desired length is ascertained and position control of each cylinder is executed as below:

$$
\begin{aligned}
& e_{1}=L_{11}-L_{1} \\
& e_{2}=L_{22}-L_{2} \\
& e_{3}=L_{33}-L_{3}
\end{aligned}
$$

\section{RESUlT AND DiscUSSION}

To validate the efficiency of the proposed model and identify system parameters, we evaluate the calculated result with the analysed result of the analytical model for the whole robot arm. As stated earlier, the following PID control scheme is embedded into the microcomputer as control modes:

$$
\begin{array}{ll}
u_{i}=\left|K_{P} e_{i}+K_{I} \int e_{i} d t+K_{D} \frac{d e_{i}}{d t}\right|+22.5 & (i=1 \sim 3) \\
\boldsymbol{e}_{i}=\boldsymbol{L}_{i m}-\boldsymbol{L}_{i s} & (i=1 \sim 3)
\end{array}
$$

Where $e_{i}[\mathrm{~m}]$ and $u_{i}[\%]$ indicate error ratio of the cylinder displacement and the duty ratio for the PWM valve in the quasi-servo valve, respectively. Table II shows the PID control parameters used for the simulation. By utilizing these selected values, the control error is able to become smaller while at the same time allowing the movement of the robot arm to be smoother.

TABLE. II. PID CONTROL PARAMETER

\begin{tabular}{|l|l|l|l|}
\hline & $\mathrm{KP}[\% / \mathrm{mm}]$ & $\mathrm{KI}[\% /(\mathrm{mm} \cdot \mathrm{s})]$ & $\mathrm{KD}[\% \cdot \mathrm{s} / \mathrm{mm}]$ \\
\hline $\begin{array}{l}\text { Master-slave } \\
\text { control }\end{array}$ & 0.79 & 1.8 & 0.01 \\
\hline
\end{tabular}


D/A converter has been developed to convert the variables output of microcomputer from digital into analog signal. The variables output voltages signify bending direction angle $\alpha$ and $\beta$ and the displacement of the cylinders, in which these are logged using a GRAPHTEC, GL200 recorder.

Fig. 7 and 8 show the calculated results of the master-slave control and trajectory control, respectively. The target values which are calculated using the proposed equations are indicated as dashed black lines based on the accelerometer's output voltages of the master arm while the calculated results are indicated as the continuous red lines. From the evaluation between the target values and the calculated values, it can be confirmed that both of the results do match.

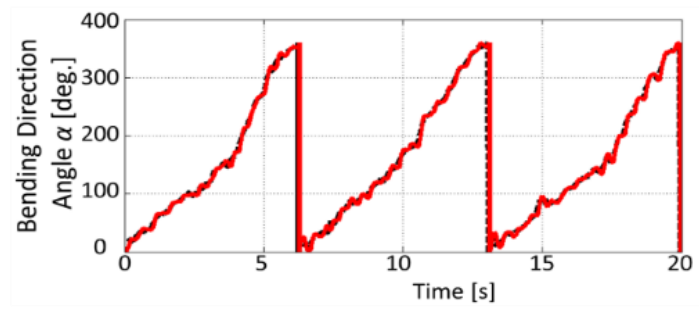

(a)

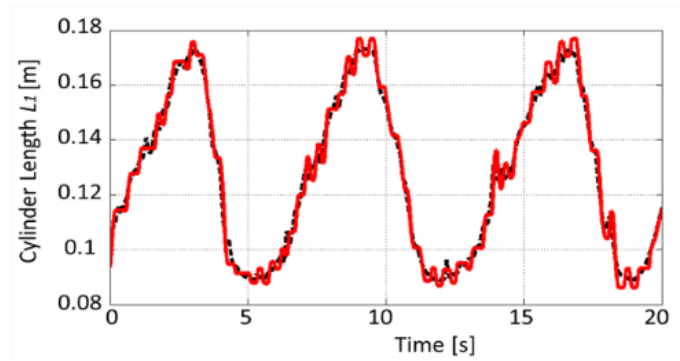

(b)

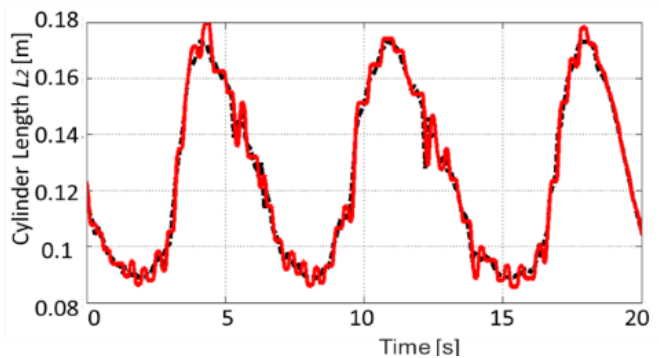

(c)

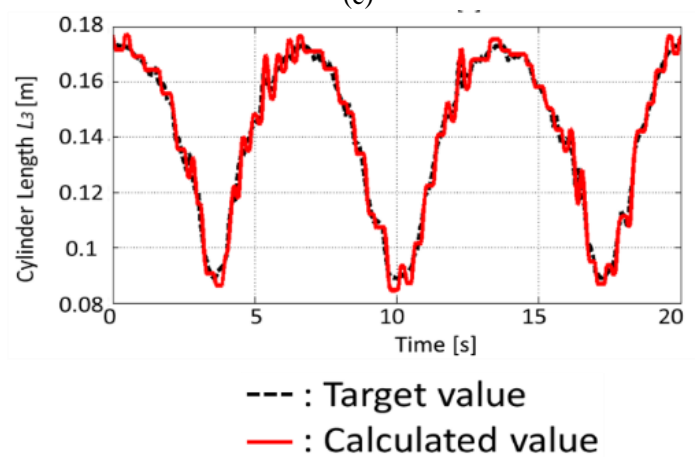

(d)

Fig. 7. Master-Slave Control Analysis; (a) Bending Direction Angle $\alpha$ Versus Time, (b) Cylinder Length, $L 1$ Versus Time, (c) Cylinder Length, $L 2$ Versus Time, (d) Cylinder Length, $L 3$ Versus Time.

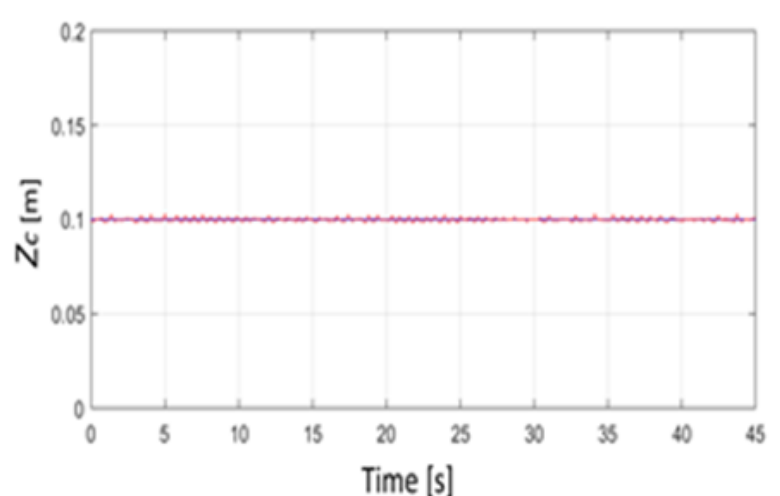

(a)

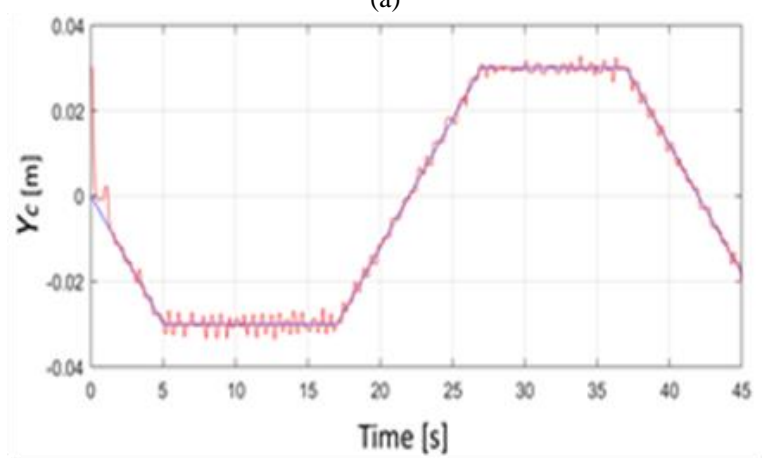

(b)

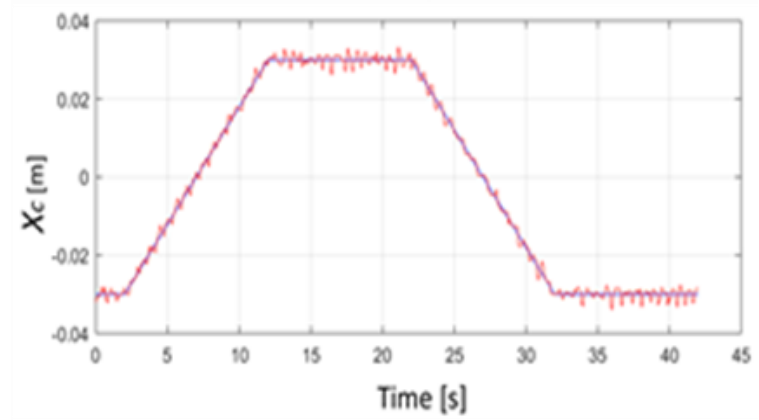

(c)

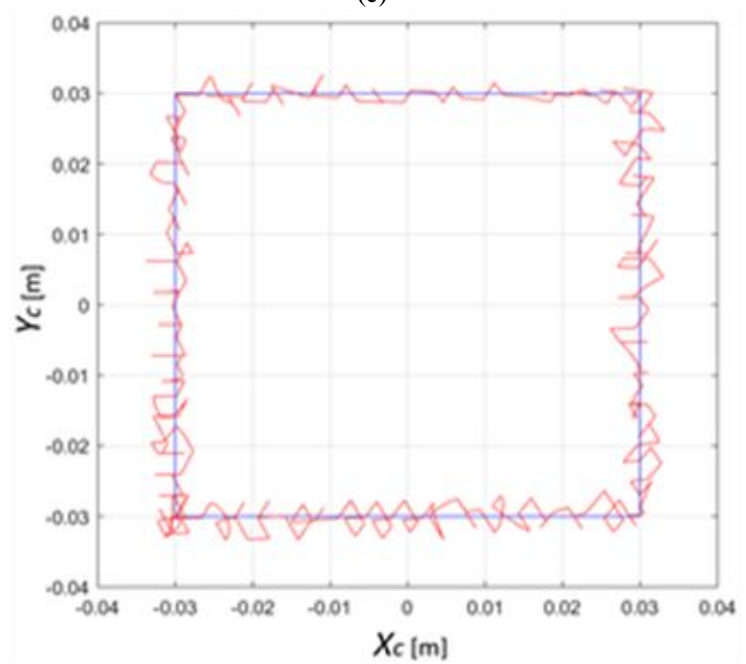

(d)

Fig. 8. Trajectory Control Analysis (a) $Z_{c}$ Versus Time,( b) $Y_{c}$ Versus Time, (c) $X_{c}$ Versus Time, $(d) Y_{c}$ Versus $X$. 


\section{CONCLUSIONS}

This study's purpose is to develop a simple, light-weight and compact rehabilitation device for human wrist that can be set up and installed by patients with less complications. It should also be applicable for home rehabilitation training program. The system is shown to consist of inexpensive quasiservo valves, a microcomputer, pneumatic robot arm and position accelerometers. Therefore, the development of flexible pneumatic robot arm for the master-slave control and trajectory control are proposed and investigated.

The simulation of the controls was performed based on our proposed analytical model. The values for PID control gain $K P, K I$ and $K D$ were investigated to achieve smaller control error, while at the same time enabling the robot arm to produce smooth movement. From our analysis and performance simulations, the calculated results agree with the desired values. From the comparison between the target values and the calculated values, we confirm that both of the results matched.

\section{ACKNOWLEDGMENT}

The authors would like to thank the Universiti Kebangsaan Malaysia and Ministry of Education Malaysia (MOE) under the Research University Grants (project code: GGPM-2017039 and FRGS/1/2018/ICT02/UKM/02/6) for funding and supporting this research.

\section{REFERENCES}

[1] W.C. Lee, A.S.A. Salam, M.F. Ibrahim, A.A.A. Rahni, and A.Z. Mohamed, "Autonomous Industrial Tank Floor Inspection Robot", IEEE International Conference on Signal and Image Processing Applications (ICSIPA), 2015, pp. 473-475.

[2] M. Makky, Delviyanti, and I. Berd, "Development of Aerial Online Intelligent Plant Monitoring System for Oil Palm (Elaeis guineensis Jacq.) Performance to External Stimuli," International Journal of Advanced Sciences Engineering Information Technology,Vol.8, 2018, pp. 2.

[3] H. Mansor, A. H. Adom, and N.A. Rahim, "Wireless Communication for Mobile Robots Using Commercial System," International Journal on Advanced Science Engineering Information Technology, Vol.2, 2012, pp. 1.

[4] R. Ramli, M.M. Yunus, and N.M. Ishak, "Robotic Teaching for Malaysian Gifted Enrichment Program," Procedia - Social and Behavioral Sciences, Vol.15, 2011, pp. 2528-2532.

[5] N. F. A. Zainal, R. Din, N. A. A. Majid, M. F. Nasrudin, and A.H.A. Rahman, "Primary and Secondary School Students Perspective on Kolbbased STEM Module and Robotic Prototype," International Journal of Advanced Sciences and Advanced Science Engineering Information Technology,Vol.8, 2018, pp. 2.

[6] Aliff, M., Yusof, M. I., Sani, N. S., \& Zainal, A, Development of Fire Fighting Robot (QRob). International Journal of Advanced Computer Science and Applications (IJACSA), 10(1), 2019.

[7] Sani, N. S., Shamsuddin, I. I. S., Sahran, S., Rahman, A. H. A and Muzaffar, E. N, Redefining selection of features and classification algorithms for room occupancy detection, International Journal on Advanced Science, Engineering and Information Technology, 8(4-2), pp. 1486-1493, 2018.
[8] Sani, N.S., Rahman, M.A., Bakar, A.A., Sahran, S. and Sarim, H.M, "Machine learning approach for bottom 40 percent households (B40) poverty classification," International Journal on Advanced Science, Engineering and Information Technology, 8(4-2), pp.1698-1705, 2018.

[9] Holliday, J. D., Sani, N., \& Willett, P. Calculation of substructural analysis weights using a genetic algorithm. Journal of chemical information and modeling, 55(2), pp. 214-221, 2015.

[10] Holliday, J. D., N. Sani, and P. Willett, Ligand-based virtual screening using a genetic algorithm with data fusion, Match: Communications in Mathematical and in Computer Chemistry, 80, pp. 623-638, 2018.

[11] J.-Y. Lee, Y.A. Song, J.Y. Jung, H.J. Kim, B.R. Kim, H.-K. Do, and J.Y. Lim, "Nurses' Needs for Care Robots in Integrated Nursing Care Services," Journal of Advanced Nursing, Vol.74, 2018, pp. 2094-2105.

[12] K.M. Goher, N. Mansouri, and S.O. Fadlallah, "Assessment of Personal Care and Medical Robots from Older Adults' Perspective," Robotics and Biomimetics,Vol.4, 2017, pp. 5.

[13] C. Bayon, R. Raya, S. L. Lara, O. Ramírez, I.S. J, and E. Rocon, "Robotic Therapies for Children with Cerebral Palsy: a Systematic Review," Translational Biomedicine, Vol.7, 2016, pp. 44.

[14] B.S. Peters, P.R. Armijo, C. Krause, S.A. Choudhury, and D. Oleynikov, "Review of Emerging Surgical Robotic Technology." Surgical Endoscopy, Vol.32, 2018, pp. 1636-1655.

[15] H. Zheng, R. Davies, H. Zhou, J. Hammerton, J. Mawson Sue, M. Ware Patricia, D. Black Norman, C. Eccleston, H. Hu, T. Stone, A. Mountain Gail, and D. Harris Nigel, "SMART project: Application of emerging information and communication technology to home-based rehabilitation for stroke patients", International Journal on Disability and Human Development. 2006. p. 271.

[16] N. Aliman, R. Ramli, and S.M. Haris, "Design and development of Lower Limb Exoskeletons: A survey." Vol.95, 2017, pp. 102-116.

[17] M. M. Said, J. Yunas, B. Bais, A. A. Hamzah, and B.Y. Majlis, "The Design, Fabrication, and Testing of an Electromagnetic Micropump with a Matrix-Patterned Magnetic Polymer Composite Actuator Membrane." Micromachines, Vol.9, 2018, pp. 13.

[18] M. Aliff, S. Dohta, and T. Akagi, "Simple Trajectory Control Method of Robot Arm Using Flexible Pneumatic Cylinders." Journal of Robotics and Mechatronics.Vol.27, 2015, pp. 698-705.

[19] S. Dohta, T. Akagi, M. Aliff, and A. Ando. "Development and Control of Simple-structured Flexible Mechanisms using Flexible Pneumatic Cylinders", IEEE/ASME International Conference on Advanced Intelligent Mechatronics, pp. 888-893, 2013.

[20] M. Aliff, S. Dohta, T. Akagi, and H. Li, "Development of a Simplestructured Pneumatic Robot Arm and its Control Using Low-cost Embedded Controller." Procedia Engineering,Vol.41, 2012, pp. 134-142.

[21] M. Aliff, S. Dohta, and T. Akagi, "Control and analysis of robot arm using flexible pneumatic cylinder." Mechanical Engineering Journal.Vol.1, 2014, pp. DR0051-DR0051.

[22] M. Aliff, S. Dohta, and T. Akagi. "Trajectory control of simplestructured flexible mechanism using flexible pneumatic cylinders", Proceedings of the 2013 IEEE/SICE International Symposium on System Integration, 2013, p. 19-24.

[23] M. Aliff, S. Dohta, T. Akagi, and T. Morimoto, "Control of Flexible Pneumatic Robot Arm Using Master Device with Pneumatic Brake Mechanism." JFPS International Journal of Fluid Power System.Vol.8, 2014, pp. 38-43.

[24] M. Aliff, S. Dohta, and T. Akagi, "Control and Analysis of Simplestructured Robot Arm using Flexible Pneumatic Cylinders." International Journal of Advanced and Applied Sciences, Vol.4, 2017, pp. 151-157. 